\title{
La imagen corporativa de las bibliotecas autonómicas españolas a través de Internet
}

\section{José Luis Herrera Morillas}

Universidad de Extremadura (España)

\section{Resumen}

De los distintos tipos de bibliotecas españolas, las autonómicas se caracterizan por ser de reciente creación, y muchas de ellas presentan una corta trayectoria. Estos centros tienen su origen en la aparición de las autonomías. Se han ido configurando a medida que las distintas comunidades autónomas han ido recibiendo competencias en materia de bibliotecas. El punto de partida de este trabajo ha consistido en comprobar cuáles de las 14 bibliotecas autonómicas existentes en España en la actualidad están presentes en Internet y de qué modo. Nos hemos detenido en aquellas que cuentan con sitios web para estudiarlos desde el punto de vista de la imagen corporativa. Para ello ha sido preciso recopilarlos y analizarlos. Hemos podido comprobar que cuentan con sitio web las siguientes bibliotecas: Biblioteca de Andalucía, Biblioteca de Aragón, Biblioteca Central de Cantabria, Biblioteca de Castilla y León, Biblioteca de Castilla - La Mancha, Biblioteca Nacional de Catalunya, Biblioteca Valenciana, Biblioteca Central de La Rioja, Biblioteca Regional de Murcia, Biblioteca General de Navarra y Centro Superior Bibliográfico de Galicia. También hemos determinado el tipo de imagen y las características del mensaje que proyectan, si el tipo de imagen corporativa reflejado es adecuado y comunica todo lo que la biblioteca es (misión, metas, recursos, servicios, infraestructuras, etcétera), y la calidad y cualidades de los recursos visuales empleados (logotipos, gama cromática, tipografías, etcétera).

Palabras clave: Bibliotecas autonómicas. España. Imagen corporativa. Internet.

\section{Abstract}

Libraries in Spanish Autonomous Regions are characterized by a very recent creation, and many of them have a very short live, what differences them from other kind of libraries. These libraries take their origin in the formation of the Autonomous Regions. They used to be founded when the regions received their competences in library matters. The starting point of this work consisted on checking which of the 14 autonomous libraries that actually exist in Spain are

Scire. $13: 1$ (en.-jun. 2007) 67-80. ISSN 1135-3716. 
present in Internet and in which way they appear. We have studied more carefully those libraries having a web site in order to study the corporate image that they offer. For this, we have first compile them, and then they have been analyzed. We have verified that the following libraries have an Internet site: Biblioteca de Andalucía, Biblioteca de Aragón, Biblioteca Central de Cantabria, Biblioteca de Castilla y León, Biblioteca de Castilla - La Mancha, Biblioteca Nacional de Catalunya, Biblioteca Valenciana, Biblioteca Central de La Rioja, Biblioteca Regional de Murcia, Biblioteca General de Navarra y Centro Superior Bibliográfico de Galicia. We have also determined the kind of image and the characteristics of the message that they project, if the corporate image reflected is appropriate and shows all what the library is (tasks, goals, resources, services, infrastructures, etc) and the quality and quantity of the visual resources used (logos, range of colours, typographies, etc).

Keywords: Spanish Autonomous Region Libraries. Spain. Corporative image. Internet.

\section{Las bibliotecas autonómicas españolas: consideraciones generales}

Las bibliotecas autonómicas españolas "son las que ocupan el vértice superior de los sistemas bibliotecarios de las comunidades autónomas y se definen en la legislación como cabeceras de dichos sistemas" (Carrión, 2000).

En la actualidad existen 14 bibliotecas autonómicas en España, y la gran parte de ellas tienen su origen en la creación de las comunidades autónomas, que va a implicar la transferencia de competencias en materia de bibliotecas y la elaboración de leyes de bibliotecas en el periodo comprendido entre 1983 y 1999.

Las bibliotecas autonómicas han sido creadas o definidas por ley o decreto (Asturias y Cantabria). La Biblioteca General de Navarra es una excepción, pues desde principios de siglo se regula por órdenes forales.

A continuación, en la tabla I, se recogen las bibliotecas autonómicas españolas ordenadas por año de creación.

Carrión (2000) clasifica las bibliotecas autonómicas atendiendo a las funciones que le asignan sus respectivas normativas legales: $a$ ) bibliotecas con funciones de biblioteca nacional; $b$ ) bibliotecas con funciones de biblioteca nacional y de apoyo a las restantes bibliotecas del sistema autonómico; $c$ ) bibliotecas con funciones de biblioteca nacional, de apoyo a las restantes bibliotecas del sistema y que ofrecen servicios de biblioteca pública.

En la actualidad 7 bibliotecas autonómicas tienen integrada una biblioteca pública.

Scire. $13: 1$ (en.-jun. 2007) 67-80. ISSN 1135-3716. 


\begin{tabular}{|l|c|}
\hline Biblioteca & Año \\
\hline Biblioteca General de Navarra & 1906 \\
\hline Biblioteca de Cataluña & 1907 \\
\hline Biblioteca de Andalucía & 1983 \\
\hline Biblioteca Valenciana & 1985 \\
\hline Biblioteca de Aragón & 1986 \\
\hline Biblioteca de Asturias & 1987 \\
\hline Biblioteca de Castilla - La Mancha & 1989 \\
\hline Biblioteca de Castilla y León & 1989 \\
\hline Biblioteca Regional de Madrid & 1989 \\
\hline Centro Superior Bibliográfico de Galicia & 1990 \\
\hline Biblioteca Central de La Rioja & 1990 \\
\hline Biblioteca Regional de Murcia & 1990 \\
\hline Biblioteca de Extremadura & 1997 \\
\hline Central de Cantabria & 1999 \\
\hline
\end{tabular}

Tabla I. Años de creación de las bibliotecas autonómicas.

\section{Imagen corporativa y bibliotecas}

La imagen corporativa es todo lo que una entidad proyecta hacia el exterior y las personas perciben, lo que los demás perciben de nosotros (bibliotecario/ biblioteca).

Toda entidad envía un mensaje al exterior, que puede ser espontáneo $-\mathrm{y}$ en este caso puede ser positivo o negativo para la institución-, o inducido o manipulado - y, lógicamente, siempre positivo-.

La imagen positiva puede suponer varias ventajas para la institución: aumentar y/o afianzar relación usuario/biblioteca; aumentar y/o justificar el presupuesto; establecer nuevas y/o mantener buenas relaciones con entidades; abrir nuevos horizontes.

Una imagen corporativa positiva se fundamenta en una imagen corporativa adecuada. Para ello se diseña una estrategia de imagen que se plasma en el "programa de imagen corporativa": "el conjunto de estudios y realizaciones orientadas a crear e implantar la imagen pública de la organización” (Costa, 1993).

Para Pizarro (2003), hay varias situaciones que hacen aconsejable un programa de imagen corporativa: a) política de diversificación, concentración o crecimiento por parte de la entidad; $b$ ) necesidad de relanzar la biblioteca o servicio, emprender nueva etapa, acceder a nuevas actividades, abrir nuevos mercados; $c$ ) deseo de afianzar o establecer relaciones entre entidades (relaciones cooperativas); $d$ ) existencia de un posicionamiento rígido o estancamiento; $e$ ) exceso de diversificación Scire. $13: 1$ (en.-jun. 2007) 67-80. ISSN 1135-3716. 
y generalidad; $f$ ) imagen existente no coherente con la identidad real; $g$ ) cambios en el estilo de dirección, objetivos y políticas; $h$ ) envejecimiento del sistema actual de identificación, que distorsiona la imagen de la entidad e impide desarrollos futuros.

En la figura 1 se recogen las técnicas de comunicación para transmitir un mensaje positivo dentro del programa de imagen (Ollins, 1991; Picazo y Evadista, 1993; Villafañe, 2002; Costa, 1995; Garbet, 1991). De todas ellas, las que van a tener una mayor presencia en las páginas y sitios web diseñados por las bibliotecas autonómicas son las de carácter visual.

\section{Técnicas de comunicación para transmitir un mensaje positivo del programa de imagen}

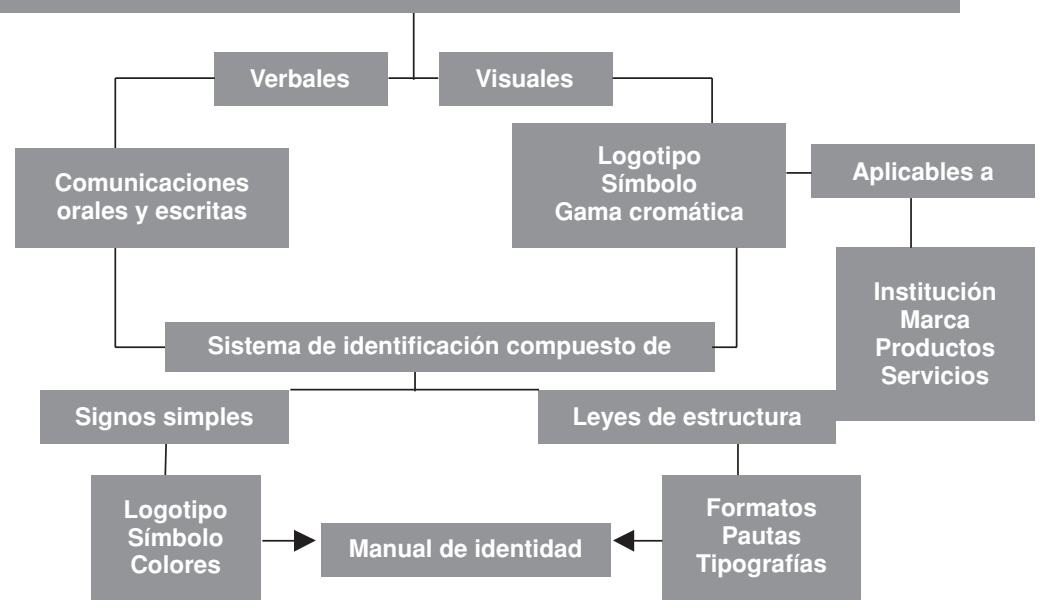

Figura 1. Técnicas de comunicación para transmitir un mensaje positivo dentro del programa de imagen.

\section{Análisis de la imagen corporativa de las bibliotecas autonómicas en Internet}

Para el estudio y análisis de cada una de las bibliotecas autonómicas hemos elaborado el siguiente esquema, que hemos utilizado en la observación directa de los sitios que presentan las bibliotecas autonómicas españolas en Internet:

- Si tiene web propia.

- Tipo de web.

- Logotipo.

- Colores.

- Fondos y diseño de las páginas.

Scire. $13: 1$ (en.-jun. 2007) 67-80. ISSN 1135-3716. 
- Elementos de identidad (metas, objetivos, recursos, servicios, personal, etcétera).

Los tipos de web los hemos diferenciado según los siguientes modelos:

- Básicas. Se limitan a presentar los datos básicos que identifican a la biblioteca; ejercen el papel de directorio. Suelen estar formadas por una sola página de escaso diseño, con un texto informativo y alguna imagen.

- Elaboradas. Diferenciamos, por un lado, las que tienen una finalidad de servir de recurso para la información y difusión, contienen información completa y detallada sobre la historia, servicios, actividades, organigrama, etcétera; reflejan lo que la institución es, su tarea y utilidades. Y, por otro lado, las que tienen una marcada tendencia a la biblioteca virtual, a través de servicios en línea, acceso a recursos virtuales, etcétera. Algunas se presentan como portales bibliotecarios. A aquellas en las que el diseño y la configuración son una mezcla de estas dos tendencias las hemos denominado mixtas.

A continuación reunimos los datos obtenidos de cada biblioteca.

\section{BIBLIOTECA DE ANDALUCÍA}

http://www.juntadeandalucia.es/cultura/ba/

Web: propia (figura 2).

Tipo: elaborada, mixta, configurada a modo de portal de recursos de información.

Servicios y recursos virtuales:

- boletín oficial;

- directorio de bibliotecas andaluzas;

- Andalucía en la Red;

- fuentes de información sobre Andalucía (base de datos);

- fondo gitano andaluz;

- cartografía histórica;

- servicio andaluz de información virtual "La biblioteca responde";

- catálogos (el propio y el de la red de bibliotecas andaluzas);

- "Entreculturas" (recursos de información para minorías étnicas y lingüísticas);

- Biblioteca Virtual de Andalucía.

Logotipo: iniciales y nombre de la biblioteca (tabla II).

Colores: blanco y verde.

Fondos y diseño de las páginas: las páginas llevan un encabezamiento de color verde con el logotipo y un menú lateral.

Elementos de identidad:

- información general (historia, funciones...);

- funciones y recursos relacionados con el patrimonio bibliográfico;

Scire. $13: 1$ (en.-jun. 2007) 67-80. ISSN 1135-3716. 
- servicios y recursos propios de una institución cabecera del sistema bibliotecario de la comunidad y de las funciones atribuidas a la biblioteca en la sociedad de la información (atención a las minorías étnicas, portal de recursos...).

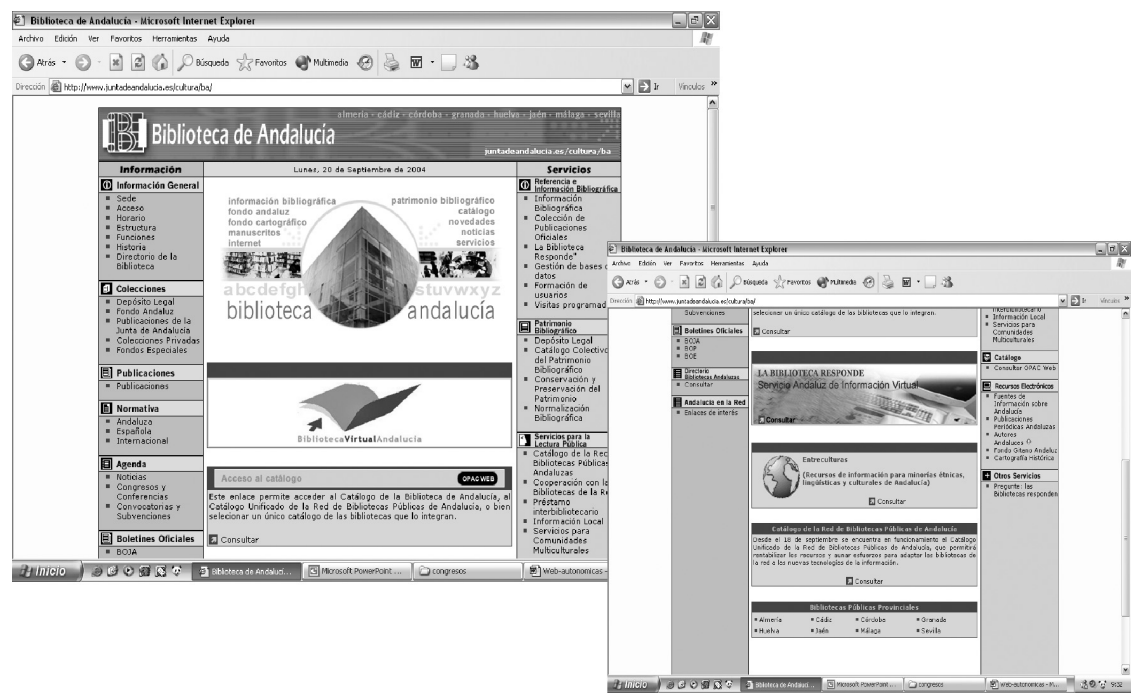

Figura 2. Web de la Biblioteca de Andalucía.

\section{BIBLIOTECA DE ARAGÓN}

http://portal.aragon.es/portal/page/portal/LIBRO/BIBARAGON

Web: no tiene web propia; es una sección del Servicio del Libro y Bibliotecas, alojada en el portal del Gobierno de Aragón; enlaza con el Instituto Bibliográfico Aragonés.

Elementos de identidad: referencias al marco jurídico.

\section{BIBLIOTECA DE CASTILLA - LA MANCHA}

http://www.jccm.es/biblioclm/

Web: propia, en dos versiones, con o sin animación flash (figura 3).

Tipo: elaborada, mixta.

Servicios y recursos virtuales:

- visita virtual;

- catálogos por secciones y tipos de fondos (infantil, local y regional, antiguo, publicaciones periódicas, lotes para clubs de lectura).

Logotipo: fachada esquematizada del edificio y, debajo, el nombre de la biblioteca (tabla II). 
Colores: azules, blanco.

Fondos y diseño de las páginas: todas las páginas tienen el mismo diseño, el menú está presente en todas, la información específica se presenta en frames, etcétera.

\section{Elementos de identidad:}

- secciones sobre el edificio, colecciones, funciones, información y documentación, directorio;

- presencia del interior del edificio por medio de fotografías, planos.

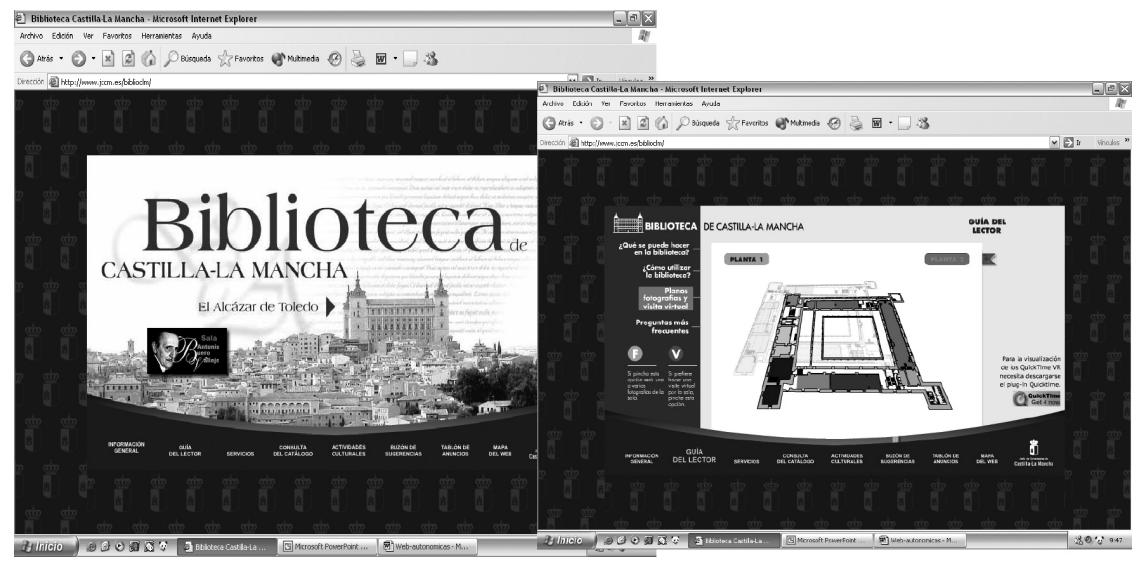

Figura 3. Web de la Biblioteca de Castilla - La Mancha.

\section{BIBLIOTECA DE CASTILLA Y LEÓN}

http://www.bcl.jcyl.es/

Web: propia.

Tipo: elaborada, mixta.

Servicios y recursos virtuales:

- catálogos: bibliotecas de Castilla y León, Biblioteca Pública de Valladolid, Catálogo Colectivo de Castilla y León, colecciones especiales (Jorge Guillén, Rosa Chacel, Martín Abril, Claudio Rodríguez, sección Biblioteconomía y Documentación, bibliografía sobre bibliobuses);

- bibliografía de Castilla y León en línea;

- bibliografías locales;

- publicaciones de la Junta de Castilla y León;

- Castilla y León en Internet;

- listas de distribución. 
Logotipo: esquema de la fachada del edificio y, debajo, el nombre de la biblioteca (tabla II).

Colores: blanco y azul.

Fondos y diseño de las páginas: todas las páginas presentan el mismo diseño: fondo blanco, margen izquierdo azul con un enlace a la página de inicio y el logotipo en el lado izquierdo del encabezamiento.

Elementos de identidad:

- apartado general “¿Qué es la biblioteca de Castilla y La Mancha?” (presentación, horario, directorio, edificio);

- los servicios y recursos que ofrece trasmiten la idea de centro de información local y regional.

\section{BIBLIOTECA DE CATALUNYA}

http://www.bnc.cat/

Web: propia.

Tipo: elaborada, mixta.

Servicios y recursos virtuales:

- documentos para algunos servicios, por ejemplo para solicitar el préstamo interbibliotecario;

- catálogos: corriente, retrospectivo, fichas electrónicas, Catálogo Colectivo del Patrimonio Bibliográfico Catalán, lista de encabezamientos de materia;

- recursos en Internet;

- exposiciones virtuales.

Logotipo: iniciales y nombre de la biblioteca (tabla II).

Colores: rojo y blanco.

Fondos y diseño de las páginas: en la portada destaca el color rojo del fondo; en el resto de las páginas el fondo es blanco y en la cabecera aparecen el menú general y el logotipo.

Elementos de identidad:

- apartado “¿Qué es la Biblioteca de Catalunya?” y otros apartados en los que se informa sobre los servicios al usuario, fondos y colecciones, servicios profesionales, proyectos...;

- opción de elegir entre el idioma catalán y el castellano;

- funciones y recursos relacionados con el patrimonio bibliográfico.

\section{CENTRO SUPERIOR BIBLIOGRÁFICO DE GALICIA}

http://www.csbg.org/

Web: en fase de realización.

Tipo: elaborada, biblioteca virtual. 
Logotipo: siglas y motivo ornamental abstracto (tabla II).

Colores: gama de grises.

Fondos y diseño de las páginas: se ha empleado el mismo para la mayoría de las secciones; en otras (depósito legal, registro de la propiedad intelectual), se enlaza a páginas independientes.

Elementos de identidad: de las secciones y recursos que pretende ofrecer se desprende la imagen de un centro al servicio del patrimonio bibliográfico:

- depósito legal.

- registro de la propiedad intelectual.

- biblioteca digital.

- bibliografía de Galicia.

\section{BIBLIOTECA DE LA RIOJA}

http://biblioteca.larioja.org/

Web: propia (pública y autonómica).

Tipo: elaborada, mixta.

Servicios y recursos virtuales:

- catálogos (biblioteca, Sibila, catálogo general de la Biblioteca de La Rioja y Catálogo Colectivo del Patrimonio Bibliográfico de La Rioja);

- otros catálogos y bibliotecas;

- estadísticas;

- revista para niños;

- sección de biblioteca para niños, con estética diferente a la del resto de la web y adaptada a este grupo de usuarios.

Logotipo: formado por un motivo figurativo esquemático (perfil de un libro y su sombra), iniciales y nombre de la biblioteca (tabla II).

Colores: gama de grises y marrones.

Fondos y diseño de las páginas: todas las páginas repiten el mismo diseño (logotipo, colores, fondo); la distinción de cada página viene dada por la incorporación de una imagen alusiva al contenido de la sección.

Elementos de identidad:

- información muy completa sobre edificio, historia, funciones, personal, estructura orgánica, normativa, estadística, etcétera;

- interrelación con la biblioteca pública; se refleja en los servicios (préstamo, fondo local, ofimática...);

- sección diferenciada para niños con diseño diferente.

Scire. $13: 1$ (en.-jun. 2007) 67-80. ISSN 1135-3716. 


\section{BIBLIOTECA REGIONAL DE MADRID JOAQUÍN LEGUINA}

http://gestiona.madrid.org/bpcm//

Web: integrada en el Servicio Regional de Bibliotecas y del Libro, donde también se accede a las webs de las bibliotecas públicas y municipales, bibliobuses y centros de lectura.

Tipo: elaborada, mixta.

Servicios y recursos virtuales:

- catálogos (biblioteca regional, bibliotecas públicas, bases de datos de coordinación y extensión bibliotecaria, catálogo de bibliobuses y Catálogo Colectivo del Patrimonio Bibliográfico).

Logotipo: motivo figurativo (perfil simplificado de un libro abierto) y nombre de la biblioteca. Es común para todas las bibliotecas del Servicio Regional; cada tipo de biblioteca se diferencia por el color del logotipo (tabla II).

Colores: cada color identifica el tipo de biblioteca: la Regional emplea el color granate. El logotipo presenta dos versiones: breve (logotipo más las iniciales de la biblioteca) o desarrollado (logotipo más el nombre de la biblioteca completo).

Fondos y diseño de las páginas: en todas las secciones el fondo es blanco; permanece fijo el diseño de la parte superior con la bandera de la Comunidad de Madrid y el nombre de la Dirección de Archivos, Bibliotecas y Museos, y también el nombre de la Biblioteca Regional sobre fondo azul. La información de cada sección se incluye en un texto corrido.

Elementos de identidad:

- apartados sobre funciones, servicios, información (“Quiénes somos”);

- de la guía de recursos que elabora se desprende la tendencia a configurarse en centro de información local y regional;

- las imágenes del edificio rehabilitado que la alberga reflejan el concepto de patrimonio recuperado.

\section{BIBLIOTECA REGIONAL DE MURCIA}

http://www.carm.es/brmu/

Web: propia.

Tipo: elaborada, mixta (organizada a modo de portal bibliotecario).

Servicios y recursos virtuales:

- catálogos (por tipos de fondos y Catálogo Colectivo de las Bibliotecas Públicas de Murcia);

- Felix, base de datos de fuentes de información en Internet y electrónicas por temas;

- catálogos en red; 
- desideratas;

- renovación;

- difusión de la información por e-mail;

- préstamo interbibliotecario;

- tablón de anuncios;

- guía de lecturas;

- web infantil diferenciada.

Logotipo: nombre completo y motivo figurativo esquemático (silueta de libros abiertos); presente en todas las páginas (tabla II).

Colores: blanco y azul.

Fondos y diseño de las páginas: todas las páginas presentan el mismo modelo (fondo blanco y, en la parte superior, el logotipo y la tipografía con el nombre de la biblioteca); la página inicial está diseñada como portal que aglutina el acceso a todos los recursos e información que ofrece la web.

Elementos de identidad: el diseño a modo de portal de recursos al servicio de la comunidad enlaza con el concepto de biblioteca pública en la sociedad de la información. No dispone de información sobre historia, funciones, etcétera.

\section{BIBLIOTECA GENERAL DE NAVARRA}

http://www.bibliotecaspublicas.es/navarra/index.jsp

Web: integrada en la de la Institución Príncipe de Viana, aunque también se puede acceder a ella directamente.

Tipo: básica, texto explicativo sobre el origen, los fondos, los usuarios...

Elementos de identidad: referencias al origen, los fondos, etcétera.

\section{BIBLIOTECA VALENCIANA}

http://bv.gva.es/screens/biblioteca_val.html

Web: propia.

Tipo: elaborada, mixta.

Servicios y recursos virtuales:

- Biblioteca Valenciana Digital;

- Catálogo Colectivo del Patrimonio Bibliográfico Valenciano;

- revista de la BV;

- biblioteca de enlaces.

Logotipo: inicial (V), con motivo abstracto y nombre de la biblioteca (tabla II).

Colores: blanco, marrón, crema.

Fondos y diseño de las páginas:

- menú con las secciones generales en el margen izquierdo; 
- menú con los apartados de cada sección en el encabezado;

- logotipo en el ángulo superior derecho.

Elementos de identidad: secciones y referencias a la historia, la colección, el edificio y el patrimonio bibliográfico valenciano; no informa sobre el personal.

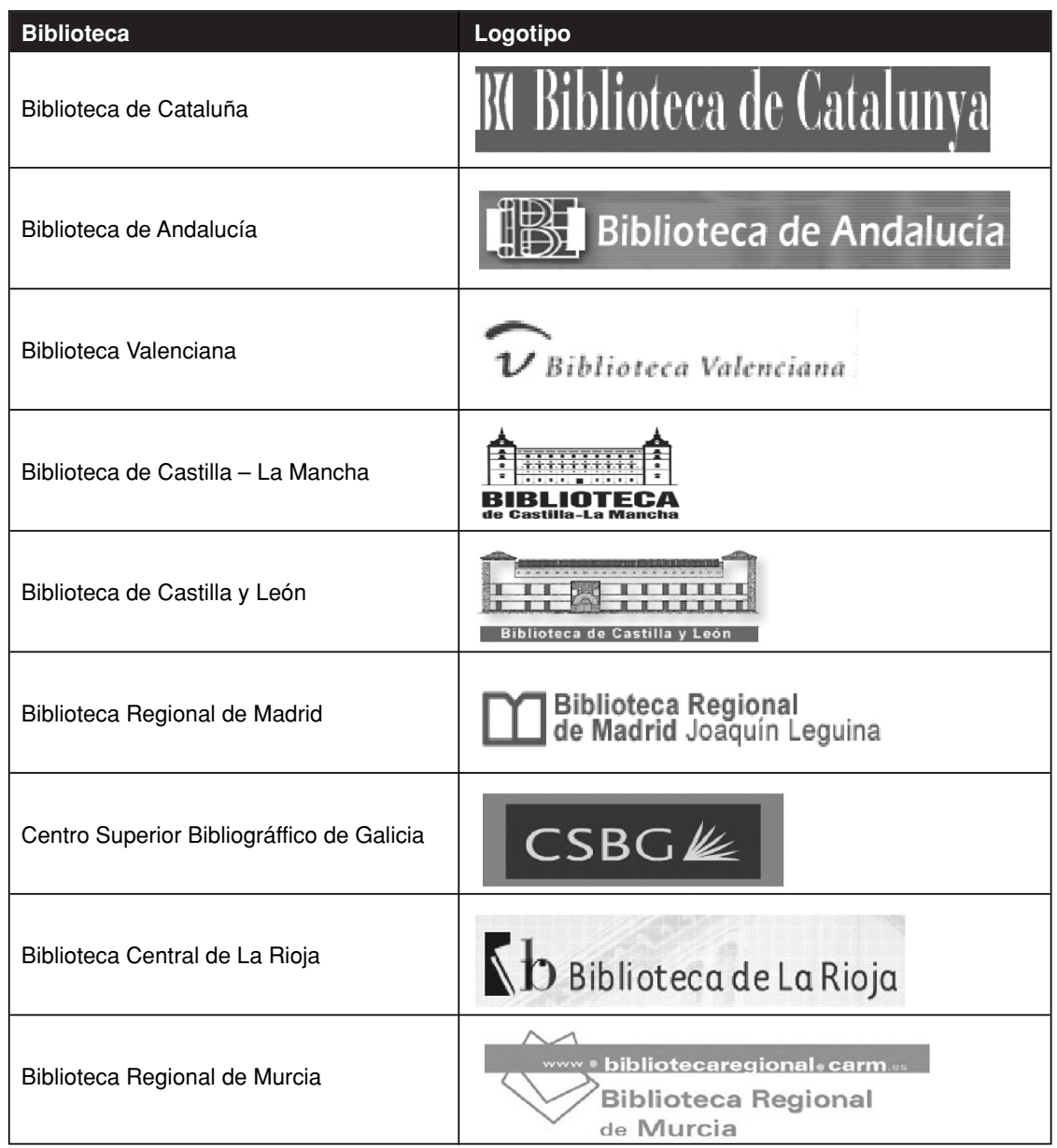

Tabla II. Logotipos. 


\section{Conclusiones}

En la actualidad, 11 de las 14 bibliotecas autonómicas españolas están presentes en Internet. Están ausentes la Biblioteca de Extremadura, la Biblioteca de Asturias Ramón Pérez de Ayala y la Biblioteca Central de Cantabria.

Según la clasificación que hemos seguido, en cuanto a tipos de web, 2 son básicas (Navarra, Aragón) y 9 elaboradas (mixta: Cataluña, Andalucía, Valencia, Castilla - La Mancha, Castilla y León, Madrid, La Rioja, Murcia; con tendencia a biblioteca virtual: Galicia).

Las páginas y sitios web elaborados por las bibliotecas autonómicas son recursos muy apropiados para reflejar la imagen corporativa, pues permiten incluir los elementos propios de la identidad visual corporativa, que suele estar compuesta de unos signos de carácter escripto-visual (logotipos), icónico (imágenes y formas gráficas) y cromático (los colores corporativos). Las bibliotecas autonómicas que cuentan con páginas elaboradas han utilizado estos signos. De todos ellos, el de mayor valor identificador es el logotipo (Miribel, 1991). Los diseñados por estas bibliotecas los podemos clasificar en varios grupos atendiendo a sus signos identificadores, tales como tipografía (normalmente el nombre de la biblioteca), anagramas (nombre abreviado de la biblioteca mediante sus iniciales), imagotipos (signos no verbales como imágenes estables y muy pregnantes que permiten una identificación que no requiere lectura, por ejemplo objetos, figuras abstractas, iconos, etcétera):

- Empleo de anagrama con las iniciales de la biblioteca y tipografía con el nombre completo de la biblioteca: 3 (Cataluña, Andalucía y Valencia).

- Imagotipo de un dibujo esquematizado de la fachada del edificio de la biblioteca y tipografía con el nombre completo de la biblioteca: 2 (Castilla La Mancha y Castilla y León).

- Imagotipo, anagrama con las iniciales de la biblioteca y nombre completo de la biblioteca: 2 (Valencia y La Rioja).

- Imagotipo y tipografía con el nombre completo de la biblioteca: 2 (Madrid y Murcia).

- Iniciales e imagotipo: 1 (Galicia).

Para finalizar citamos a Gómez y Saorín (2003), para quienes la transmisión de contenidos, en el marco cultural de la sociedad de masas, se produce a través de múltiples canales complementarios. Todos ellos pueden ser utilizados para potenciar los mensajes que se quieran transmitir sobre las bibliotecas: la gestión de la comunicación no puede quedarse únicamente en la elaboración rutinaria de notas de prensa, sino que hay que saltar hacia una acción integral de comunicación: difusión de imagen institucional a través de logotipos, inserción de medios de comunicación interactivos como Internet, uso de estereotipos positivos mediáticos de

Scire. $13: 1$ (en.-jun. 2007) 67-80. ISSN 1135-3716. 
ficción para la intervención sobre el cambio de imagen de las bibliotecas, uso de los mensajes emotivos y artísticos, y, sobre todo, acercamiento a los mediadores de la comunicación para conseguir la producción de mensajes de mayor calidad.

\section{Referencias}

Carrión Gútiez, A. (2000). Las bibliotecas autonómicas. // Boletín de la Anabad. 50:3-4 (2000) 9-80.

Costa, J. (1993). Identidad corporativa. México: Trillas, 1993.

Costa, J. (1995). Comunicación corporativa. Madrid: Ediciones Sociales, 1995.

Garbet, F. T. (1991). Imagen corporativa (cómo crearla y proyectarla). Bogotá: Legis, 1991.

Gómez Hernández, J. A.; Saorín Pérez, T (2003). La imagen actual de las bibliotecas públicas en la cultura de masas. http://gti1.edu.um.es:8080/jgomez/bibgen/intranet/ imagenbiblioteca.PDF (2004-12-15).

Miribel, M. de (1991). L'image des bibliothèques publiques à travers les logos. // Argus. 8:2 (1999) 11-21.

Ollins, W. (1991). Identidad corporativa. Madrid: Celeste, 1991.

Picazo, M. L.; Evadista, L. G. (1993). Comunicación estratégica (para crear, fortalecer y posicionar la imagen corporativa). México: McGraw Hill, 1993.

Pizarro Bonilla, L. (2003). La imagen corporativa, una estrategia del nuevo perfil del bibliotecario. // El Profesional de la Información. 12:6 (nov.-dic. 1992) 464-466.

Villafañe, J. (2002). Imagen positiva. La gestión estratégica de la imagen de las empresas. Madrid: Pirámide, 2002. 